\title{
THE POPULATION DYNAMICS OF GENETICALLY DETER- MINED RESISTANCE TO WARFARIN IN RATTUS NORVEGICUS FROM MID WALES
}

\author{
J. A. BISHOP, D. J. HARTLEY and G. G. PARTRIDGE \\ Department of Genetics, University of Liverpool, Liverpool L69 3BX
}

Received 23.iii.77

\section{SUMmary}

Dominant warfarin resistance and a recessive haemorrhagic trait are apparently controlled by the same allele $R w^{2}$.

Twenty-eight $\mathrm{F}_{2}$ litters and 18 backcross litters of wild rats were scored for resistance when 8 weeks of age. There was a deficiency of resistant males in the $F_{2}$ litters whereas phenotypic ratios were close to expectation in $F_{2}$ females and backcrosses. Any deficiency of resistant males in $\mathrm{F}_{2}$ litters could be due to the selective death of the $R w^{2} R w^{2}$ genotype. The size of $\mathrm{F}_{2}$ and backcross litters at birth is similar whereas by 8 weeks the former are significantly smaller than the latter.

Samples of rats from populations in mid Wales were scored for resistance. There was a significant decline in the frequency of phenotypic resistance in one large population $(\mathcal{N} \approx 500)$ starting when the frequency of the $R w^{2}$ allele was relatively low $(c .0 \cdot 10-0 \cdot 23)$. Since few alleles can be lost by selective death of $R w^{2} R w^{2}$ males in these circumstances it appears that, in the absence of warfarin, the heterozygote may also be at a selective disadvantage.

Where rats are intensively poisoned with warfarin both $R w^{2}$ and its alternative $R w^{1}$ are maintained in populations by heterozygous advantage. The ecological unreality of the concept of segregational load is discussed.

Strong selection influences the frequency of the alleles of $R w$. Chance must also have an important role. Populations of rats in rural areas are widely scattered and sometimes small in size. There is an unpredictable amount of movement between these populations which occur in very heterogeneous environments.

\section{INTRODUGTION}

BLOoD clots seal the wounds of mammals. Clotting is controlled by a biochemically and genetically complex process whereby a number of precursor factors are involved in the production of an insoluble fibrin clot. Anticoagulant drugs disrupt this system and overdoses of such chemicals are used to kill pest species of rodents. The drug warfarin was introduced as a rodenticide in the United Kingdom in 1953 and inevitably rodent populations evolved genetically-determined resistance to it. Amongst the earliest instances of such resistance were those observed in populations of Rattus norvegicus (Berkenhout) from Scotland (1958) and from the English-Welsh border (1959).

Resistance in rats from Wales is dominant and controlled by an autosomal gene mapping at about the same site as an allele determining a recessive haemorrhagic trait (Dunning and Curtis, 1939; Greaves and Ayres, 1967, 1969). Greaves and Ayres (1969) and Hermodson, Suttie and Link (1969) have discussed the interrelationship and it seems likely that these characters are pleitropic effects of the same gene. Warfarin-resistant rats 
were found to have an increased requiremcnt for vitamin $\mathrm{K}$. Heterozygotes needed between two and three times and the resistant homozygote nearly 20 times the amount required by the susceptible homozygotes. Under some circumstances resistant homozygotes will not be able to obtain sufficient vitamin $\mathrm{K}$ and this will result in haemorrhages typical of vitamin deficiency. Hermodson et al. (1969) further suggest that warfarin acts via its influence on the vitamin $\mathrm{K}$-dependent clotting factors. Their hypothesis is that a protein necessary for clotting factor synthesis interacts with both vitamin $\mathrm{K}$ and warfarin and that the latter is antagonistic to the normal action of the vitamin. In heterozygous rats some of this protein is altered and both substances have lcss affinity for it; however, the affinity with warfarin is reduced relatively more than the affinity with vitamin $\mathrm{K}$. Homozygous resistant rats would possess only altered protein and so would synthesise $\mathrm{K}$-dependent clotting factors very inefficiently. This would manifest itself in a requirement for large quantities of vitamin $\mathrm{K}$ and in the recessive haemorrhagic trait discussed above. An alternative hypothesis (Bell and Caldwell, 1973; Zimmerman and Matschiner, 1974) suggests that warfarin inhibits the synthesis of $\mathrm{K}$-dependent clotting factors by causing the natural metabolite of vitamin $\mathrm{K}$ to accumulate. This metabolite (vitamin $\mathrm{K}_{2}$, 3-epoxide) is reduced to vitamin $\mathrm{K}$ by a reductase which is different in resistant and in susceptible rats. Zimmerman and Matschiner found that the reductase of resistant rats was less inhibited by warfarin than that of the susceptible rats. This hypothesis seems the most likely and it forms the basis of a most satisfactory test for distinguishing susceptible and resistant animals (see next section).

Bishop and Hartley (1976) and Hartley and Bishop (1978) discuss the dynamics of a number of wild populations of $R$. norvegicus, polymorphic for warfarin resistance, that occur on farms in mid Wales. The present paper discusses further aspects of the formal genetics of the mutant allele and examines some aspects of the dynamics of the gene in these populations.

\section{METHODS}

Successful breeding of wild $R$. norvegicus was difficult under animal house conditions. Matings were relatively unsuccessful during winter months and occasionally newborn litters would be abandoned by their mothers. In the latter situation it was sometimes possible to provide an albino (laboratory stock) foster mother.

All crosses were based on eight resistant and six susceptible females and five resistant and five susceptible males collected from populations at Forden, Powys (Bishop and Harley, 1976). These populations were not, to our knowledge, poisoned with warfarin during our study and it is possible (Greaves, personal communication) that they had not been poisoned with the substance for several years prior to the start of our investigation in 1972.

Phenotypic resistance of progeny of all crosses was established by the method of Bell and Caldwell (1973) and Martin, Steed, Redfern and Gill (1977). This involved injecting animals with a mixed solution of warfarin $(5 \mathrm{mg} / \mathrm{kg}$ ) and vitamin $\mathrm{K}$ oxide $(1 \mathrm{mg} / \mathrm{kg})$. The clotting time of each test animal was determined both before and 24 hours after injection.

Blood samples $(0.2 \mathrm{ml})$ were obtained from lightly etherised animals by cutting the tail tip and, after discarding the first drop, collecting the blood 
in a calibrated microtube containing sodium citrate solution. The whole blood-clotting time was determined using Diagen Two-Seven-Ten reagent (Diagnostic Reagents Ltd) on a Fibrometer coagulation timer (Becton, Dickinson \& Co.). Percentage clotting activity (PCA) for the sample was calculated by reference to standard curves which were prepared beforehand for each batch of reagent. Curves were drawn for each sex by pooling blood from six Wistar males and six females respectively and measuring the clotting time of serial dilutions of this blood.

Animals could readily be assigned to the resistant and susceptible classes after the $\mathrm{K}$ oxide/warfarin injection. One group (susceptible) had PCA values of $<10$ per cent whereas the other group (resistant) had values of $>20$ per cent. Resistant animals frequently had low resting levels (0-20 per cent) but on $\mathrm{K}$ oxide/warfarin administration all these animals increased their PCA value to $>20$ per cent. This illustrates the advantage of injecting $\mathrm{K}$ oxide as well as warfarin to determine phenotype. The resistant rat is able to re-cycle the $\mathrm{K}$ oxide probably because its reductase is altered and not susceptible to warfarin inhibition. The susceptible rat, however, cannot overcome the warfarin block and clotting factor synthesis is prevented.

The injection test was compared with the standard 6-day feeding test for warfarin resistance as described by Drummond and Wilson (1968). Seventeen animals were assigned to resistant and susceptible classes after the $\mathrm{K}$ oxide/warfarin test (12 and 5 respectively). After 2 weeks' recovery these animals were subject to a 6 -day feeding test $(0.005$ per cent warfarin in medium oatmeal) at the end of which only the previously designated susceptible animals had died. The 12 resistant animals were all feeding normally.

Injection test animals and all stock were fed on pelleted diet $41 \mathrm{~B}$, and water was provided ad lib. All stock was kept under standard animal house conditions.

The number of offspring in each litter was recorded at birth (for fostered families), at 4 weeks (for families with their natural mother) and at 8 weeks in all cases at which time the phenotypes of all progeny with respect to resistance was ascertained.

Populations of rats were studied and sampled at Forden, Powys, using techniques described by Bishop and Hartley (1976). Rats sampled from the populations were scored by the 6-day feeding test (see above) until September 1974. Thereafter the K oxide/warfarin test was used.

\section{Results}

Table 1 records the progeny of 28 crosses between confirmed heterozygous parents. There is a non-significant deficiency in the resistant class and when these data are compared with those of Hermodson et al. (1969) they are found to be similar. Although the data are limited there is some suggestion that either the resistant homozygote $\left(R w^{2} R w^{2}\right)$ is severely deleterious under animal house conditions, or that some resistant animals are being classified as suceptibles.

The individual crosses listed in table 1 show great variability in frequency of resistance; some of this may be due to chance and some may be the result of the heterogeneous genetic background in which the resistance allele of 
TABLE 1

Phenotypes of progeny of matings between Rattus norvegicus heterozygous for the $\mathrm{Rw}^{2}$ allele $\left(F_{\mathrm{2}}\right.$ crosses)

\begin{tabular}{|c|c|c|c|c|c|c|c|c|c|}
\hline \multirow{2}{*}{$\begin{array}{c}\text { Cross } \\
\text { No. }\end{array}$} & \multicolumn{2}{|c|}{ Parents } & & \multicolumn{2}{|c|}{$\begin{array}{c}\text { Rcsistant } \\
\left(R w^{2} R w^{2} \text { or } R w^{2} R w^{1}\right)\end{array}$} & \multicolumn{2}{|c|}{$\begin{array}{l}\text { Susceptible } \\
\left(R w^{1} R w^{1}\right)\end{array}$} & \multicolumn{2}{|c|}{$\begin{array}{l}\text { Litter size at birth } \\
\text { (fostered families) } \\
\quad \text { or at } 4 \text { weeks }\end{array}$} \\
\hline & Father & Mother & & 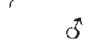 & 우 & $\overrightarrow{0}$ & 우 & 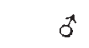 & q \\
\hline 1 & 1 & 2 & $\mathrm{~F}$ & 2 & 5 & 0 & 0 & \multicolumn{2}{|c|}{9} \\
\hline 2 & 3 & 8 & $\mathrm{~F}$ & 1 & 1 & 0 & 3 & \multicolumn{2}{|c|}{11} \\
\hline 3 & 3 & 4 & $\mathrm{~F}$ & 0 & 1 & 2 & 3 & \multicolumn{2}{|c|}{12} \\
\hline 4 & 3 & 4 & & 2 & 4 & 2 & 2 & 5 & 6 \\
\hline 5 & 5 & 2 & & 2 & 1 & 0 & 0 & 2 & 1 \\
\hline 6 & 1 & 6 & $\mathbf{F}$ & 1 & 2 & 0 & 0 & \multicolumn{2}{|c|}{6} \\
\hline 7 & 1 & 8 & $F$ & 1 & 3 & 2 & 0 & 3 & 3 \\
\hline 8 & 7 & 22 & $\mathrm{~F}$ & 2 & 1 & 1 & 0 & \multicolumn{2}{|c|}{12} \\
\hline 9 & 1 & 6 & & 2 & 1 & 0 & 1 & 2 & 2 \\
\hline 10 & 7 & 2 & $\mathrm{~F}$ & 1 & 4 & 1 & 0 & 3 & 4 \\
\hline 11 & 3 & 2 & & 2 & 2 & 1 & 1 & 4 & 3 \\
\hline 12 & 1 & 6 & $F$ & 0 & 2 & 1 & 1 & \multicolumn{2}{|c|}{9} \\
\hline 13 & 1 & 12 & & 0 & 0 & 0 & 2 & 6 & 5 \\
\hline 14 & 1 & 4 & & 3 & 2 & 0 & 0 & 4 & 2 \\
\hline 15 & 7 & 22 & & 0 & 4 & 2 & 0 & 2 & 4 \\
\hline 16 & No. $2 \mathrm{~J}$ & 6 & & 3 & 2 & 2 & 0 & \multirow{2}{*}{$\begin{array}{l}5 \\
6\end{array}$} & 2 \\
\hline 17 & No. $2 \mathrm{~J}$ & No. $1 \mathrm{D}$ & & 4 & 2 & 2 & 0 & & 2 \\
\hline 18 & 3 & 2 & & 3 & 2 & 1 & 3 & 4 & 5 \\
\hline 19 & 7 & 9 & & 3 & 6 & 0 & 2 & \multirow{2}{*}{$\begin{array}{l}3 \\
3\end{array}$} & 9 \\
\hline 20 & 3 & No. $1 \mathrm{~B}$ & & 0 & 4 & 3 & 0 & & 4 \\
\hline 21 & No. $2 \mathrm{~J}$ & No. $8 \mathrm{~B}$ & & 0 & 5 & 0 & 1 & 0 & 7 \\
\hline 22 & 7 & 8 & & 3 & 2 & 2 & 0 & 6 & 3 \\
\hline 23 & No. $17 \mathrm{~F}$ & No. $96 \mathrm{~F}$ & $F$ & 4 & 1 & 2 & 0 & 6 & 1 \\
\hline 24 & No. $14 \mathrm{E}$ & No. $10 \Lambda$ & & 2 & 2 & 0 & 0 & 3 & 3 \\
\hline 25 & No. $4 \mathrm{~F}$ & No. $97 \mathrm{C}$ & & 0 & 1 & 1 & 0 & 1 & 2 \\
\hline 26 & No. $98 \mathrm{C}$ & No. $15 \mathrm{D}$ & & 3 & 2 & 2 & 0 & 5 & 2 \\
\hline 27 & No. $98 \mathrm{G}$ & No. $20 \mathrm{E}$ & & 7 & 0 & 0 & 1 & $\begin{array}{l}7 \\
3\end{array}$ & 1 \\
\hline 28 & No. $96 \mathrm{~A}$ & No. 99 I & & 2 & 2 & 1 & 0 & \multirow[t]{2}{*}{3} & 3 \\
\hline & & & & 53 & 65 & 28 & 20 & & \\
\hline
\end{tabular}

$\begin{array}{ll}\text { Test of hypothesis of } 1: 1 \text { sex ratio } & \chi_{1}^{2}=0.386 \text { n.s. } \\ \text { Test of fit to } 3: 1 \text { ratio (males and females) } & \chi_{1}^{2}=1.357 \text { n.s. } \\ \text { Test of fit to } 3: 1 \text { ratio (fcmales) } & \chi_{1}^{2}=0.098 \text { n.s. } \\ \text { Test of fit to } 3: 1 \text { ratio (males) } & \chi_{1}^{2}=3.955 \text { P }<0.05\end{array}$

Fostered litters are indicated by $\mathrm{F}$. All crosses are given an identification number. The series is continued in table 2 and all rats are identified by a number or, if reared in captivity, by their original litter number and an alphabetic character (e.g. No. $2 \mathrm{~J}$ ).

Litters 96 to 99 were produced for another experiment unconnected with this paper.

The rats coded 5 (Cross 5) and No. $14 \mathrm{E}$ (Cross 24) werc confirmed as heterozygotes by scoring progeny of their backcross to susceptible.

The following litters were born in indicated periods: 1 (Dec. 1973), 2-22 (Feb.-Aug. 1975), 23-28 (Mar.-July 1976). There is a significant interaction between sex and year of birth; there was a deficiency of males born in 1975 and a surplus in 1976. The reason for this is not known.

the field-caught rats that we used in our breeding programme occurs. When the frequency of resistance is considered separately in the two sexes there is a significant deficiency $(P=0.05)$ of resistant $F_{2}$ males whereas the ratio is close to Mendelian expectation (3:1) in females. Any deleterious effect 
of homozygous $\left(R w^{2} R w^{2}\right)$ may therefore be sex limited to males, though the frequency of resistance in the two sexes does not itself differ significantly $\left(\chi^{2}=2 \cdot 46\right)$.

When resistant heterozygotes $\left(R w^{2} R w^{1}\right)$ were backcrossed to warfarinsusceptible rats $\left(R w^{1} R w^{1}\right)$ a $1: 1$ ratio of resistant to susceptible progeny was obtained (table 2).

If natural selection is eliminating homozygous resistant males by the time they are 8 weeks old, death must obviously occur during intrauterine

TABLE 2

Phenotypes in litters of $\mathrm{Rw}^{1} \mathrm{R} \mathrm{w}^{2}$ rats backcrossed to $\mathrm{R} w^{1} \mathrm{R} w^{1}$ genotype

\begin{tabular}{|c|c|c|c|c|c|c|c|c|c|}
\hline \multirow{2}{*}{$\begin{array}{c}\text { Cross } \\
\text { No. }\end{array}$} & \multicolumn{2}{|c|}{$\begin{aligned} \quad \text { Parents } \\
\mathrm{S}=\text { Susceptible } \\
\mathrm{R}=\text { Resistant }\end{aligned}$} & & & $\begin{array}{l}\text { Resistant } \\
\left(R w^{2} R w^{1}\right)\end{array}$ & \multicolumn{2}{|c|}{$\begin{array}{l}\text { Susceptible } \\
\quad\left(R w^{1} R w^{1}\right)\end{array}$} & \multicolumn{2}{|c|}{$\begin{array}{l}\text { Litter size at birth } \\
\text { (fostered families) } \\
\text { or at } 4 \text { weeks }\end{array}$} \\
\hline & Father & Mother & & 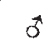 & $q$ & $\sigma$ & 우 & 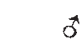 & q \\
\hline 29 & $10(\mathrm{~S})$ & $14(\mathrm{R})$ & $\mathbf{F}$ & 2 & 0 & 1 & 1 & 3 & 1 \\
\hline 30 & 11 (R) & $15(\mathrm{~S})$ & $\mathrm{F}$ & 3 & 0 & 2 & 2 & 5 & 2 \\
\hline 31 & $3(\mathrm{R})$ & $16(S)$ & $\mathrm{F}$ & 1 & 2 & 4 & 0 & 6 & 2 \\
\hline 32 & 23 (S) & $4(\mathrm{R})$ & & 1 & 3 & 1 & 3 & 3 & 6 \\
\hline 33 & $13(\mathrm{~S})$ & $8(\mathrm{R})$ & $\mathrm{F}$ & 1 & 0 & 0 & 1 & 1 & 1 \\
\hline 34 & $3(\mathrm{R})$ & $15(\mathrm{~S})$ & & 0 & 4 & 3 & 2 & 3 & 6 \\
\hline 35 & $1(\mathrm{R})$ & $16(\mathrm{~S})$ & $\mathrm{F}$ & 2 & 4 & 0 & 2 & 6 & 6 \\
\hline 36 & $1(\mathrm{R})$ & $17(\mathrm{~S})$ & & 3 & 1 & 6 & 4 & 9 & 5 \\
\hline 37 & 3 (R) & $18(\mathrm{~S})$ & & 2 & 2 & 5 & 2 & 7 & 4 \\
\hline 38 & 7 (R) & $19(S)$ & & 1 & 4 & 1 & 1 & 2 & 5 \\
\hline 39 & $7(\mathrm{R})$ & $19(\mathrm{~S})$ & & 4 & l & 0 & 3 & 4 & 4 \\
\hline 40 & $3(\mathrm{R})$ & $20(\mathrm{~S})$ & $\mathrm{F}$ & 1 & $i$ & 1 & 2 & 5 & 6 \\
\hline 41 & $3(\mathrm{R})$ & $20(S)$ & & 1 & 0 & 3 & 2 & 4 & 2 \\
\hline 42 & No. 4 I (S) & No. $18 \mathrm{~B}(\mathrm{R})$ & & 4 & 1 & 1 & 0 & 5 & 2 \\
\hline 43 & $24(\mathrm{~S})$ & No. $9 \mathrm{~A}(\mathrm{R})$ & $\mathrm{F}$ & 1 & 1 & 2 & 2 & & \\
\hline 44 & $21(S)$ & No. $97 \mathrm{C}(\mathrm{R})$ & & 3 & 3 & 1 & 4 & 4 & 7 \\
\hline 45 & 21 (S) & No. $10 \mathrm{~A}(\mathrm{R})$ & & 2 & 4 & 2 & 0 & 4 & 4 \\
\hline 46 & $21(S)$ & No. $99 \mathrm{C}(\mathrm{R})$ & & 0 & 0 & $2^{*}$ & 0 & 3 & $5 *$ \\
\hline & & & & 32 & 31 & 35 & 31 & & \\
\hline
\end{tabular}

* At 7 weeks there were eight in this litter but six died immediately prior to test.

Fostered litters are designated with an F.

Progeny were scored at 8 weeks of age. Where offspring of previous crosses are used, the litter number is indicated in the "Parents" columns.

The following litters were born in indicated periods: 29 (Nov. 1974), 30-41 (Apr.-Sept. 1975), 42-46 (May-Aug. 1976).

life and/or during the postnatal period. The loss of homozygotes could be detected in either event by comparing the litter sizes of the progeny of $\mathrm{F}_{2}$ and backcross matings at birth and at 8 weeks.

Table 3 shows that, at birth, $F_{2}$ litters are, in fact, non-significantly greater in numbers than backcross ones; at 4 weeks they are non-significantly smaller in size and by 8 weeks of age this difference has become significant. Families reared by their natural mother are considered at 4 and 8 weeks whereas the comparison is made between fostered litters at birth. (We were anxious to disturb newborn families as little as possible and there was higher mortality in fostered litters that tended to obscure the differences in size

$39 / 3-F$ 
between the two types of litter (table 3).) These results suggest that selection against the $R w^{2} R w^{2}$ genotype occurs during the postnatal life of such individuals. The reduction in litter size is, in fact, greater than one would expect if the male $R w^{2} R w^{2}$ rats were lethal. The backcross littcr were similar in size to those produced by female rats sampled, at random with respect to their alleles at the $R w$ locus, at Forden (table 4) Bishop and Hartley, 1976, p. 642).

Table 4 records the number of rcsistant and susceptible rats found in the farm buildings at Upper Min-y-llyn, Forden. The frequency of $R w^{2}$ was approximately 0.23 in Dccember 1972, so by Hardy-Weinberg expectation only about 0.05 of the zygotes produced at that time could have had the $R w^{2} R w^{2}$ genotypc. Few $R w^{2}$ alleles could therefore have been lost by

\section{TABLE 3}

Litter sizes of $F_{2}$ and backcross matings of warfarin resistant Rattus norvegicus at birth, 4 weeks and 8 weeks of age. ( \pm standard deviations)

Time

\begin{tabular}{|c|c|c|c|c|}
\hline $\begin{array}{l}\text { Genotype of } \\
\text { parents } \\
\left(\mathrm{F}_{2}\right) \\
R w^{1} R w^{2} \times R w^{1} R w^{2}\end{array}$ & & $\begin{array}{l}\text { Genotype of } \\
\text { parents } \\
\text { (backcross) } \\
R w^{1} R w^{1} \times R w^{1} R w^{2} \\
\text { (or rcciprocal) }\end{array}$ & $t^{*}$ & $\mathrm{P}$ \\
\hline $8 \cdot 67$ & 9 & 8.1 & & \\
\hline & 11 & & & \\
\hline $6 \cdot 16$ & $\therefore 1$ & & -2 & \\
\hline $5.33 \pm 1.4$ & 7 & $5 \cdot 5$ & -0.214 & \\
\hline $5.895 \pm 2 \cdot 22$ & 18 & $7 \cdot 50 \pm 2 \cdot 73$ & $-2 \cdot 192$ & \\
\hline
\end{tabular}

Litters that were provided with foster mothers were counted at birth (1), litters with natural mothers were counted when 4 weeks old (at weaning) (2), and when scored for resistance (3). Fostered litters were also scored for resistance at 8 wceks (4). The sizes of $F_{2}$ and backcross litters reared by foster mothers tended, because of higher mortality, to be smaller than the corresponding litters reared by natural mothers $(t=-0.9165$, n.s. $t=-2.850, \mathrm{P}<0.001$ respcctively).

The litter sizes at birth of pregnant females taken from Upper Min-y-llyn to Liverpool was $8 \cdot 09 \pm 2 \cdot 81$ (Bishop and Hartley, 1976).

Full data appear in tables 1 and 2. Matings of the two types were contemporaneous.

* $t$-tests examine the hypothesis that the litter size of the $\mathrm{F}_{2}$ and backcross matings is the same.

death of homozygous males yet there was a substantial drop in the frequency of resistant rats between 1972 and the end of 1975. Many rats were present in the buildings at this time and it is unlikely that the change was due to sampling drift. A possible explanation is that in thc absence of warfarin heterozygous animals are at a disadvantagc to the susceptible homozygotes. In August and September 1973 there was an increase in frequency of resistant rats in the building. The reasons for this are not clear; two possibilities are that, unknown to us, warfarin may have been used against rats or that successful immigrants may have carried in the gcne.

Resistant rats also occur in the hedges adjacent to the farm (table 4) although this population is, in part, separated from that in the buildings by only the width of a road $(5 \mathrm{~m})$. The frequency of resistance in the populations can be significantly different (e.g. December 1974). 
TABLE 4

Number of warfarin resistant rats in samples from two adjacent populations at the upper farm

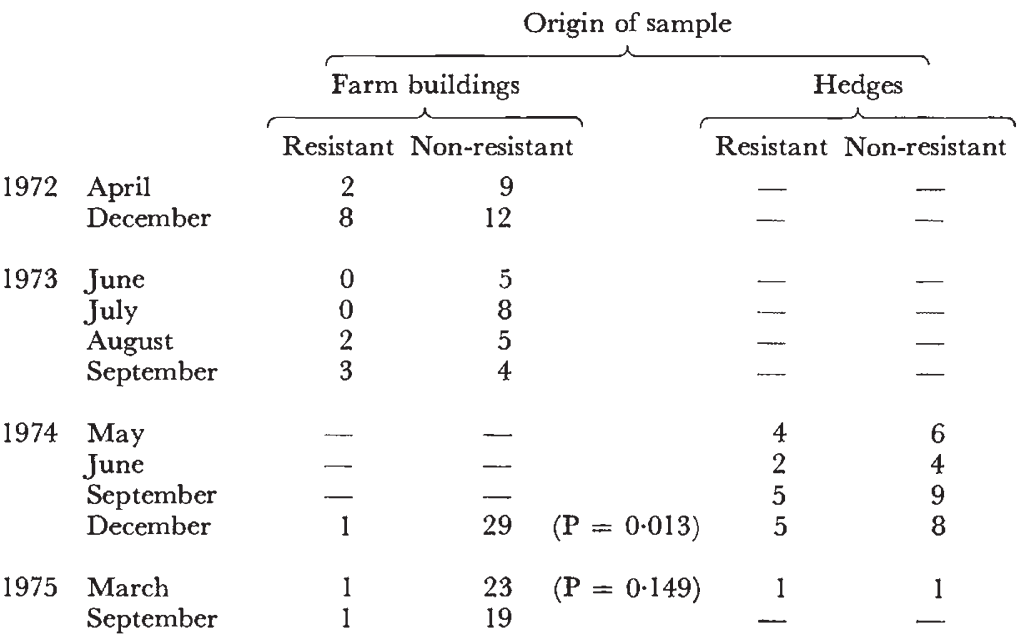

The combined data for each year $(1972-75)$ are significantly heterogeneous $\left(\chi_{3}^{2}=12 \cdot 32\right.$ (corrected for continuity); $\mathrm{P}<0 \cdot 01$ ).

The probabilities (Dec. 1974, Mar. 1975) are for exact tests comparing frequency of resistance in samples taken from the two populations at the same time. The null hypothesis in each case is that the frequency of resistance in the two appropriate samples is the same.

\section{Discussion}

The method of scoring used by Hermodson et al. (1969) occasionally misclassifies resistant animals as being warfarin susceptible and some of the shortfall of resistant animals in their $\mathrm{F}_{2}$ progeny may have been due to this. Our method is unlikely to produce such effects; indeed we found that after warfarin/ $K$ oxide injection the percentage clotting activity of the two phenotypes did not overlap. The departure from Mendelian expectation in our $\mathrm{F}_{2}$ 's must therefore be due to the lowered viability of the $R w^{2} R w^{2}$ genotype. Greaves (personal communication) found no such deficiency of resistant animals in $\mathrm{F}_{2}$ crosses made in his laboratory. Two hypotheses may be suggested to account for this. Firstly, his stock was relatively genetically homogeneous in that the $R w^{2}$ allele was incorporated into Wistar. Many generations of animal house existence may have selected modifier genes that have enabled the $R w^{2} R w^{2}$ animals to be more successful in the peculiar conditions of such an environment. Secondly, his animals were scored at 6 weeks of age whereas ours were examined at 8 weeks. Selective elimination of the resistant homozygotes may have not progressed far enough to be detected by 6 weeks (table 3 ).

Mellette and Leone (1960) found that different strains and sexes of rat showed varying degrees of susceptibility to the haemorrhagic trait associated with vitamin $\mathrm{K}$ deficiency. This suggests that modifiers can extensively influence the production of the K-dependent clotting factors. Wallace and MacSwinney (1976) describe a major gene War of the house mouse homo- 
logous with thc $R w^{2}$ allele in the rat. They present evidence that modifiers influencc expression of this gene.

Where warfarin is used against a population containing the $R w^{1}$ and $R w^{2}$ alleles it appears that heterozygous advantage could maintain both in a stable polymorphism. The removal of the unfit homozygotes by poisoning or deficiency disease might be considered to impose a segregational load on the population which can be measured by the shortfall below maximum output of young. In an intensively poisoned population almost all $R w^{1} R w^{1}$ rats will die from the effects of warfarin, $R w^{2} R w^{2}$ males from deficiency discase. If the frequency of phenotypic resistance is about 0.6 the deficiency in output will be about 47 per cent compared with a population fixed for $R w$ in the absence of warfarin. Since this genctically induced loss is largely incurred after birth, it suggests that the reproductive performance of populations polymorphic for resistance could be substantially impaired by this load.

Fraser and Mayo (1974) discuss segregational load in the context of sickle-ccll anaemia and the polymorphism for haemoglobins $\mathrm{A}$ and $\mathrm{S}$ in man. (This is another case in which the fittest genotype is the heterozygote.) They express reservations as to which of a number of estimates of load, embodying different ecological and genetic assumptions, is the most meaningful. The same doubts are relevant here; indeed they are even more acute since the selective forces maintaining the polymorphism can be so readily altered by man. Powerful sclection against homozygotes may not severely impair recruitment to our populations. Bishop and Hartley (1976, p. 637) found that the survival rate of rats in nature is low. The mean expectation of life at first capture in a capture-recapture experiment was about 2.0 months for males and about 2.6 months for females. Since females produce their first litters at about 4 to 5 months of age a large proportion of animals must die before reproducing. At lcast part of this loss must be due to the action of density-dependent factors and genetic death may therefore bc compensated for by a reduction in mortality caused by such factors.

Where use of warfarin is discontinued the frequency of resistance is likely to decline at a rate determined by the fitness of the $R w^{1} R w^{2}$ and $R w^{2} R w^{2}$ genotypes relative to the susceptible $R w^{1} R w^{1}$. The fitness of all genotypes will, of course, be dependent on the particular environment of individuals in the population concerned. In real life there will be strong though intermittent selcction against the susceptible homozygotes.

'The frequency of the $R r^{2}$ allele can be markedly differcnt in adjacent populations (e.g. table 4). There are a number of reasons for this. lirstly, it is difficult for hedge rats to establish themselves indoors. Even after intensive poisoning of the population in the buildings the populations remain discrete; the indoor one appcars to inhibit the permanent ingress of outsiders (Bishop and Hartley, 1976; Hartley and Bishop, 1978). Secondly, the rats in the buildings reproduced throughout a period when the hedge rats were reproductively quiescent (Bishop and Hartley, 1976, p. 636). Even if the frequency of resistance was initially similar in the two populations and the selective forces were the same, selection acting against resistant homozygotes would cause the frequency of the $R w^{2}$ allcle in the actively reproducing population to decline in relation to the quiescent one. Thirdly, the environments of the two populations are very different; rats in the building 
have an abundant supply of grain food which is deficient in vitamin $\mathrm{K}$ (Partridge, unpublished). Rats in hedges may feed on green vegetation containing the vitamin. Further studies on the feeding habits of the two populations of rats would be desirable to determine the likely intake of vitamin $\mathrm{K}$ by animals in the two populations and the subsequent fitness of the genotypes in the appropriate environments. Normally, although to our knowledge it did not occur in the present case, farm rats will be subject to warfarin poisoning and selection for resistance whereas rats in hedges will not be subject to such rodenticide treatment.

In addition to these directed changes in gene frequency, the size and structure of rat populations at Forden (Bishop and Hartley, 1976) suggest that migration and sampling drift (Wright, 1931; Cain and Currey, 1963) might have a significant influence on the abundance of the $R w^{2}$ allele.

Only some individuals in a population are of reproductive age. The effective breeding size of populations, which takes account of the numbers of mature animals and their sex, is frequently a small fraction of their numerical size. Thus the largest field population at Forden (Bishop and Hartley, 1976) sometimes had a low effective size. In June 1972 and March 1973, for instance, the numerical size was 68 and 34 but the effective size was seven in each case. The small populations rarely consisted of more than five reproductively mature animals. The chance establishment of a single, reproductively active, male carrying the $R w^{2}$ allele in such a population could substantially increase the frequency of resistance in it.

There is a mosaic of rat populations in the lowlands of the Welsh-English borders. These populations vary in size from a few to 500 or more resident individuals and at some time the most marginal populations will become extinct and their habitat will later be re-colonised. As well as resident rats there is a substantial number of wandering individuals, largely male, seeking a permanent living place. Some of these establish home ranges, either where a previous population has died out or in an existing population, while the great majority die without reproducing. The movement of such individuals is likely to be the chief means of dispersal of the $R w^{2}$ allele. Most of these transient rats appear in August to November (autumn) (Bishop and Hartley, 1976, pp. 638-639; Hartley and Bishop, 1978).

This polymorphism is clearly maintained by complex selective forces. Superimposed is a stochastic element which arises because of the structure and distribution of the populations and of the amount of successful migration between them.

Acknowledgments.-We wish to express our thanks to officers of the Pest Infestation Control Laboratory of the Ministry of Agriculture Fisheries and Food. In particular we are grateful for the assistance of J. H. Greaves, A. D. Martin, R. Redfern, B. Rennison and N. Wallace.

L. M. Cook, J. H. Greaves and O. Mayo offered valuable criticism of the maunscript; Carol Keill provided technical assistance and Denise O'Leary prepared the typescript.

Theresearch was financed by N.E.R.C. and by The Royal Society. G. G. P. was an S.R.C. research student.

\section{ReFERENCES}

BELL, R. G., AND CALDWELL, P. T. 1973. Mechanism of warfarin resistance. Warfarin and the metabolism of vitamin $\mathrm{K}_{1}$. Biochemistry, 12, 1759-1762.

BISHOP, J. A., AND KARTLEY, D. J. 1976. The size and age structure of rural populations 
of Rattus norvegicus containing individuals resitant to the anticoagulant poison warfarin. J. Anim. Ecol., 45, 623-646.

cain, A. J., And currey, J. D. 1963. Area effects in Cepaea. Phil. Trans. R. Soc. Lond. B., $246,1-81$.

DRUMMOND, D. C., AND WILSON, E. J. 1968. Laboratory investigations of resistance to warfarin of Rattus norvegicus in Montgomeryshire and Shropshire. Ann. Applied Biol., $61,303-349$.

DUNNING, W. F., AND CURTIS, M. R. 1939. Linkage in rats between factors determining a pathological condition and a coat colour. Genetics, 24,70 .

FRASER, G. R., AND MAYO, o. 1974. Genetical load in man. Humangenetik, 23, 83-110.

GREAVES, J. H., AND AYRES, P. 1967. Heritable resistance to warfarin in rats. Nature, Lond., 215, 877-878.

GREAVES, J. H., AND AYREs, P. 1969. Linkages between genes for coat colour and resistance to warfarin in Rattus norvegicus. Nature, Lond., 224, 284-285.

HARTLEY, D. J., AND BISHOP, J. A. 1978. Home range and patterns of movement in rural populations of the brown rat Rattus norvegicus (Berkenhout). F. Linn. Soc. (in press).

IIERMODSON, M. A., SUTTIE, J. W., AND LINK, K. P. 1969. Warfarin metabolism and vitamin $\mathrm{K}$ requirement in the warfarin-resistant rat. Am. F. Physiol., 217, 1316-1319.

MARTIN, A. D., STFED, L. C., REDFERN, R., AND GILl, E. 1977. Genotype determination in warfarin resistant rats. Lab. anim. (in press).

MELLETTE, S. J., AND LEONE, L. A. 1960. Influence of age, sex, strain of rat and fat soluble vitamins on haemorrhagic syndromes in rats fed irradiated beef. Fedn. Proc., 19, 1045-1049.

WALLACE, M. E., AND MACSWINNEY, F. J. 1976. A major gene controlling warfarin-resistance in the house mouse. F. Hyg., Camb., 76, 173-181.

WRIGHT, s. 1931. Evolution in Mendelian populations. Genetics, 16, 97-159.

ZIMMERMAN, A., AND MATSCHINER, J. T., 1974. Biochemical basis of hereditary resistance to warfarin in the rat. Biochem. Pharmacol., 23, 1033-1040. 